\title{
ENTRE O TEXTO E O CONTEXTO: OS GÊNEROS TEXTUAIS NOS LIVROS DIDÁTICOS “CONHECENDO O SEMIÁRIDO 1 E 2" PARA A APRENDIZAGEM CONTEXTUALIZADA
}

\author{
ROSIANE ROCHA OLIVEIRA \\ Mestra e especialista em Educação, pedagoga pela Universidade do Estado da Bahia. Coordenadora do Selo Editorial \\ RESAB. Professora da Faculdade de Ciências Aplicadas e Sociais de Petrolina/PE. E-mail: rosi.rocha@facape.br \\ EDMERSON DOS SANTOS REIS \\ Doutor, mestre e pedagogo pela Universidade Federal da Bahia. Professor adjunto do Departamento de Ciências \\ Humanas da Universidade do Estado da Bahia. Coordenador do Programa de Pós- Graduação - Mestrado em Educação, \\ Cultura e Territórios Semiárido da Universidade do Estado da Bahia. E-mail: edmerson.uneb@gmail.com
}

\begin{abstract}
RESUMO
O presente trabalho traz uma reflexão sobre as contribuições dos gêneros textuais presentes nos livros didáticos "Conhecendo o Semiárido 1 e 2" da Rede de Educação do Semiárido Brasileiro (RESAB) para a aprendizagem contextualizada do educando. A pesquisa foi realizada com base em análise dos livros didáticos "Conhecendo o Semiárido 1 e 2" e entrevista com as autoras desse material. Em suma pode-se avaliar a presença diversificada de gêneros textuais nesses livros didáticos, com o intuito de trazer em sua essência a desconstrução de conceitos estereotipados historicamente estigmatizados sobre as realidades do Semiárido Brasileiro. A proposta central do trabalho é a abordagem de uma Educação Contextualizada, enquanto elemento de reorientação curricular que possobilite aos sujeitos conhecer suas realidades através dessa variedade de gêneros textuais percebendo-se enquanto sujeitos de atuação do seu processo de ensino/aprendizagem. Apesar de o trabalho ter um foco que se pauta pelas novas lingugens utilizadas nos materiais analisados, não nos eximimos de trazer uma categórica análise histórica do processo de formação do Semiárido Brasileiro em suas condições políticas e sociais, bem como ventilamos discussões sobre Educação Contextualizada enquanto proposta de reorientação curricular, uma vez que essas temáticas são pontos cruciais que contribuem para a produção de um material didático contextualizado.
\end{abstract}

Palavras-chave: Gêneros textuais; Livros Didáticos; Linguagem Contextualizada.

\section{BETWEEN TEXT AND CONTEXT: THE GENRES IN TEXTBOOKS "KNOWING SEMIARID CONDITIONS 1 AND 2" FOR CONTEXTUALIZED LEARNING}

\begin{abstract}
This paper reflects about the contributions of genres present in textbooks "Knowing Semiarid conditions 1 and 2" of the Rede de Educação do Semiárido Brasileiro (RESAB) or Brazilian Semiarid Education Network for contextualized learning of the student. The research was based on analysis of textbooks "Knowing Semiarid conditions 1 and 2" and interview with the authors of this material. In short we can assess the presence of diverse genres in these textbooks, in order to bring in its essence the deconstruction of stereotypical concepts historically stigmatized about the realities of the Brazilian Semiarid region. The central purpose of this study is to approach a Contextualized Education as curriculum reorientation element possobilite the subjects know their realities through this variety of genres perceiving themselves as subjects of activity of their teaching/learning process. Although the work has a focus that is guided by new lingugens used in the materials analyzed, do not we disclaim bring a categorical historical analysis of the Brazilian semiarid region of the training process in their political and social conditions, as well as ventilate discussions Contextualized Education as proposed curriculum reorientation, since these issues are crucial points that contribute to the production of educational material in context.
\end{abstract}

Keywords: Text Genres ; Didatic Books; Contextualized Language. 


\section{Introdução}

A preocupação com a educação de qualidade no Semiárido Brasileiro emerge a partir de discussões entre professores, universidades, movimentos sociais e outras instituições que compreendem a Educação como um fator essencial à desconstrução do pensamento colonialista impregnado nas práticas escolares reforçando a concepção de que o Semiárido é o lugar do atraso (SILVA, 2010). Essa nova perspectiva constrói-se pelo viés da Educação Contextualizada para a Convivência com o Semiárido, compreendida como um fator fundamental para a garantia da qualidade que se busca na Educação nesse território.

Sob essa perspectiva, o presente trabalho corrobora que a base para uma Educação de qualidade precisa ser, entre outros fatores, contextualizada (ou seja, estar conectada à realidade dos sujeitos aprendentes) e descolonizada (das narrativas eurocêntricas, sexistas, classicistas, etc.). Esse olhar é também permeado pela ideia de que:

Forjar uma educação de qualidade é também investir na construção de um currículo
descolonizado e contextualizado. Descolonizar o currículo passa por romper com o seu
caráter preconceituoso, que desconsidera o negro, que apresenta o índio como símbolo da
preguiça, que fundamenta os livros didáticos em produto do mercado e não de facilitador da
aprendizagem e de acesso ao conhecimento. Sendo assim, é preciso descolonizar essas
ideias e essas imagens que fazem parte do contexto da produção do livro didático. (REIS,
2010, p. 126).

Essa educação de qualidade significa ter interesse por melhorar qualidade de vida das pessoas, de todas as pessoas, pois "na educação, a qualidade está ligada diretamente ao bem-viver de todas as nossas comunidades, a partir da comunidade escolar" (GADOTTI, 2010, p. 07) ou seja, uma melhoria na educação para que esta seja de qualidade passa necessariamente, dentre outros fatores, pelas condições de aprendizagem dos educandos, pelos significados que estão atrelados à aprendizagem, a melhoria da qualidade de vida e à emancipação social.

Para a escrita do presente trabalho optamos pela abordagem qualitativa e a pesquisa documental (análise dos livros didáticos “Conhecendo o Semiárido 1 e 2") com realização de entrevistas (com as três autoras dos livros) como itinerário metodológico que em tempo apresentouse como opção viável à realização da pesquisa. Além disso o projeto foi devidamente submetido ao comitê de ética da Plataforma Brasil, por meio do qual as entrevistadas assinaram os Termos de Consentimento Livre e Esclarecido, dando-nos a liberdade de utilização dos seus nomes reais para a apresentação dos dados coletados e apresentados nos resultados do presente trabalho. Esperamos que este possa contribuir para as percepções acerca dos materiais didáticos como possibilidades de 
contextualização onde o uso dos gêneros textuais seja um dos facilitadores dessa aprendizagem contextualizada.

\section{De que lugar falamos}

O Brasil está dividido em 05 regiões: Norte, Nordeste, Centro-oeste, Sudeste e Sul; a região Nordeste abrange 09 estados do Brasil: Alagoas, Bahia, Ceará, Maranhão, Paraíba, Pernambuco, Piauí, Rio Grande do Norte e Sergipe. O Brasil ainda possui uma subdivisão que são os complexos regionais: Amazônia, Nordeste e Centro-sul; o complexo nordestino é geograficamente delineado em quatro sub-regiões: Agreste, Meio-Norte, Sertão e Zona da Mata. O Sertão é a sub-região que ocupa maior parte do Nordeste; tem prevalência de clima Semiárido e possui o único bioma exclusivamente brasileiro a Caatinga. O Semiárido comporta 1.133 municípios dos estados nordestinos e ocupa uma área de $969.589,4 \mathrm{~km}^{2}$ que representa $15,72 \%$ do território nacional (CARVALHO \& SCHISTEK, 2011).

Nesse sentido, para além da realidade atual do Semiárido, precisamos discorrer, mesmo que brevemente, as influências históricas que passaram a atuar diretamente na construção dos dizeres sobre esse território, pois é necessário perceber como, historicamente, as intervenções coloniais, governamentais e políticas interferiram nos processos formativos histórico-sociais do Semiárido Brasileiro. Para tal, é preciso compreender que, inicialmente as primeiras famílias que habitaram o Semiárido Brasileiro eram famílias indígenas Macro-Jê; essas famílias viviam em um sistema nômade e mantinham uma relação de harmonia com a natureza, pois utilizavam seus recursos de maneira sustentável (SANTOS, 2010).

Alves 1982 afirma que já em 1587 quando se dá o primeiro registro de seca, pode-se notar registros de famílias indígenas migrando do Sertão para o litoral em busca de alimentos. Sobre isso Silva (2006, p. 35) reforça quando afirma que tal fato "chamou a atenção dos colonizadores a grande quantidade de índios que vinham do Sertão para o litoral, fugindo da seca”. Com os processos gerais de colonização no Brasil e a entrada dos colonizadores especificamente nas veredas do Sertão a cultura indígena foi sofrendo processos de mutilação, principalmente porque os europeus eram dotados da pólvora (SANTOS, 2010).

Esse processo de entrada dos colonizadores no Semiárido Brasileiro (SAB) se dá cerca dos anos 1650, segundo Silva (2006), através dos principais movimentos como a ocupação de áreas do Agreste com a policultura e pecuária para abastecer a região açucareira; as expedições de 
exploração de minério às margens do São Francisco (o que abriu caminho para a atividade pecuária); e a fuga de colonizadores do litoral para o sertão na época da ocupação holandesa. Com o extermínio de inúmeras famílias nativas e a fuga de outras, os dominadores passaram a fundar arraiais e dominar a exploração do minério na região do São Francisco. Nesse enredo, passaram a receber concessões de terras e exercício de domínio sobre os recursos naturais onde "a destruição do modo de vida dos povos indígenas ocorria na medida em que a 'civilização' branca avançava" (SILVA, 2006, p. 39), e só com o enraizamento dessa população branca no SAB é que a seca passou a ter visibilidade e ser considerada como problema relevante no século XVIII.

É nesse ponto que condenam a seca como fator substancialmente prejudicial às fazendas de gado e agravante para a calamidade, a fome e prejuízos aos colonizadores. Já aí se impregnam os primeiros estereótipos sobre as gentes do Sertão, pois os pedidos de recursos ao Reino Português fizeram com que o rei de Portugal e seus conselheiros interpretassem que a fome e a escassez de alimentos se configuravam pela preguiça e ociosidade dos moradores do Sertão (SILVA, 2006).

Desde então, sempre atreladas politicamente às questões financeiras, as secas ou estiagens mais prolongadas e as disputas pelas sesmarias eram, segundo Menezes (1970), fatores prejudiciais e agravantes da condição econômica do Semiárido Brasileiro. É nessa conjuntura de disputas que os poderes responsáveis passam a tomar algumas medidas para estudo sobre as maneiras de combate à seca e formas de assistência aos povos que viviam as consequências das secas, mas também consequências de uma ocupação desordenada e desordenadora de um modo de vida que já estava estabelecido, como foi dito, de maneira sustentável e numa relação de convivência não exploratória pelas famílias nativas.

No entanto, as medidas eram descontínuas, assistencialistas e imediatistas para ajudar a população local a "sobreviver". Só no final do século passado a postura estatal começa a mudar, criando órgãos permanentes, mas que eram de combate às secas. É esse ponto que inaugura a grande problemática que gerou um atraso em relação aos estudos de viabilidade de vida com qualidade no Semiárido, pois as chuvas, a neve ou o frio, as secas e estiagens são fatores também potencialmente naturais e não podem ser combatidos. Compreender que não se pode combater a natureza e/ou seus fenômenos, mas mitigar os efeitos que ela pode gerar deveria ser a pauta desde os primeiros estudos e políticas.

Há cerca de 30 anos emergem as discussões sobre as possibilidades de Convivência com o Semiárido Brasileiro e o viés da Educação tem sido pautado por organizações governamentais e não governamentais como elemento potencializador dessa proposta, o que contribuiu significativamente 
para o desdobramento da institucionalização da Rede de Educação do Semiárido Brasileiro (RESAB) nos anos 2000.

Nesse movimento em torno da proposição da Educação Contextualizada para Convivência com o Semiárido Brasileiro, alguns movimentos sociais e instituições públicas parceiras vêm se organizando em redes, e a RESAB se apresenta como um dos mais estratégicos mecanismos de mobilização dos debates e ações encampadas em direção a uma reinvenção do fazer escolar a partir da proposição para a articulação de políticas públicas em ECSAB. Essa rede e seus movimentos se avultam na tentativa de romper o contexto histórico de produção de estereótipos em torno do povo do Semiárido gerando uma nova premissa afirmando que é possível conviver com o Semiárido, com qualidade e não somente "sobreviver", compreendendo que não fazemos parte de um único Semiárido, de única identidade sofredora e flagelada (SENA, 2012). Pois de acordo com esses aspectos do passado, atualmente a imagem veiculada do Semiárido Brasileiro é caricaturada e, como afirma Reis (2010, p. 112) “a imprensa nacional e os que escreveram sobre esta região, tendo como parâmetros apenas uma época do ano, ou apenas um ângulo da região, não perceberam a sua complexidade", mas continuam reproduzindo e reforçando tais estigmas.

Com base nesses processos históricos é que vão se formando as concepções sobre o Nordeste e são essas concepções que vão sendo disseminadas ao longo do tempo. Os aspectos sociais e políticos que se referem aos nordestinos são apresentados, nos livros didáticos, de formas estereotipadas, estigmatizadas. Partindo desse pressuposto, cabe afirmar que é indispensável promover uma políticas públicas educacionais para a ressignificação do Semiárido Brasileiro no imaginário social das pessoas que aprenderam (com a mídia, as artes literárias, os livros didáticos e ainda reforçados pela ausência de políticas públicas) que o Semiárido é inviável e, consequentemente, não têm esse sentimento de pertença por não conhecerem a existência da potencialidade dos múltiplos Semiáridos (urbanos, rurais, tradicionais, contemporâneos, entre tantas facetas).

Assim, se os instrumentos que formam e informam sobre o lugar em que pisamos demonstram esta particularidade, como a escola e os docentes poderão fazer diferente, se isso é o que possuem de referências, daquilo que oficialmente chega aos sistemas e às escolas? Pensemos sobre tais questões para propor novas estratégias de saídas às suas problemáticas.

É sob o viés que de concepção e uma outra Educação no Semiárido Brasileiro que Lins (2010, p. 17) descreve esse paradigma da Convivência com o Semiárido como sendo: 
Um causo inventado por homens e mulheres que descobriram radicalmente que não tinham mais como sustentar a mentira do combate à seca, essa sim, soava como mentira de verdade, porque a seca não se combate, considerando que se trata de um fenômeno natural do clima. Um causo inventado por homens e mulheres, e contado com os corpos, com os sonhos e com a vontade de mudar as histórias acontecidas e narradas sobre essa região, nos vários lugares onde escoam para as páginas oficiais, os registros sobre os lugares, as pessoas e as coisas do Sertão Nordestino.

Nesse contexto, algumas iniciativas pessoais de profissionais, de instituições governamentais e não governamentais, e, por conseguinte a aderência das próprias instituições, foram articulando-se rizomaticamente ${ }^{1}$ a partir das experiências de Educação Popular, por onde se começou a levantar o questionamento do formato universalista de ensino, que não tocava nas lutas de classes, nem levava em consideração as diversidades e múltiplas contextualidades presentes no âmbito escolar (PEREIRA, 2012), e este foi o sentido de discutir várias propostas de contextualização do ensino, inclusive "De pé no chão também se aprende a ler" com Paulo Freire em Angicos/RN, que aconteceu na década de 1960 (REIS, 2007).

Ademais, teceremos ao longo deste trabalho, os processos históricos de constituição do livro didático como um material necessário ao desenvolvimento da prática pedagógica, mas, principalmente sob a ótica da contextualização desses materiais, a possibilidade do próprio livro didático ser um elemento de desconstrução dos estigmas historicamente disseminados sobre as realidades brasileiras e, mais especificamente do Semiárido Brasileiro.

\section{Outros olhares sobre as potencialidades do Semiárido Brasileiro na Educação}

De certo, as produções de livros didáticos e materiais paradidáticos, com a perspectiva da contextualização, ganham força junto às movimentações que ocorreram na década de 1990, pois a esse período, a produção de cartilhas instrucionais e outros materiais paradidáticos que pautavam a Convivência com o Semiárido Brasileiro, já realizadas por algumas instituições, e a criação da Articulação do Semiárido Brasileiro (ASA) em 1999, foram alavancas para esse processo. Tais práticas consolidaram-se de uma melhor forma no trabalho realizado pelo (Instituto Regional da Pequena Agropecuária Apropriada) IRPAA, que apesar de inicialmente ${ }^{2}$ ser mais técnico que pedagógico, já percebia a necessidade de materializar as discussões de modo que esses materiais elaborados seriam utilizados para a produção de um conhecimento contra hegemônico, por perceber que:

\footnotetext{
1“'O rizoma é horizontalidade que multiplica as relações e os intercâmbios que dele se originam. A vida assim compreendida é um contínuo fluxo e refluxo, potência de interação e produção de sentidos." (LINS, 2005, p. 1232).

${ }^{2}$ Fundado em 1990 o IRPAA possuía, inicialmente, trabalhos de atuação com agricultoras e agricultores com cunho técnico para o desenvolvimento e apropriação de tecnologias de Convivência com o Semiárido Brasileiro, destacando as potencialidades de vida e produção nesse lugar. Em 1999, o instituto implantou o Eixo de Educação para ofertar uma formação diferenciada a professoras e professores das comunidades beneficiadas com a assistência técnica do instituto.
} 
O material didático disponibilizado ao aluno (livros e outros) tem sido totalmente descontextualizado, negligenciando a realidade local (as especificidades e potencialidades do Semiárido). O livro e outros materiais que contemplem a realidade são de fundamental importância para que o aluno possa se sentir protagonista no processo educacional e na construção da identidade. (RESAB, 2006, p. 20)

Com essa visão, a implementação do Eixo de Educação no IRPAA veio alavancar as novas formas de perceber o Semiárido nas escolas e as formas como o mesmo era disseminado através dos materiais utilizados nestas, principalmente por via do livro didático, o que caracterizava um processo de colonização dos sujeitos que deles compartiam. Enxergando essas e outras tantas questões, o IRPAA vai proporcionar junto às secretarias de educação uma proposta diferenciada para a formação de educadoras e educadores no Semiárido Brasileiro, como parte integrante da RESAB e pautando-se por um dos 04 eixos norteadores da Rede, no caso a formação de professores, utilizando-se também dos materiais já produzidos.

Dizemos aqui da criação dos livros "Conhecendo o Semiárido 1 e 2" pelo IRPAA e às vezes nos referimos ao IRPAA ou à RESAB porque no processo de criação desses livros foi o IRPAA quem assumiu sua responsabilidade jurídica, uma vez que não tendo a RESAB personalidade jurídica, necessitou de uma instituição que pudesse assumir a produção desses materiais. Nesse caso, a responsabilidade jurídica dos livros “Conhecendo o Semiárido 1 e 2" credita-se ao IRPAA, mas a responsabilidade política à RESAB.

Esses materiais, no entanto, até então compunham apenas o quadro de materiais técnicos e paradidáticos (PIMENTEL, 2002) colaborando com a formação das educadoras e educadores fora da sala de aula e subsidiando sua prática apenas até certo ponto. Com o fortalecimento das discussões sobre a Educação Contextualizada no Eixo de Educação o IRPAA, enquanto uma das instituições da estrutura rizomática da RESAB, vai criando outros materiais para subsidiar a formação dos professores e suas práticas no ambiente escolar. Ambientes esses que ainda careciam de um material diferenciado de sustentação à prática pedagógica. Compreendendo ainda que:

$\mathrm{Na}$ elaboração do livro didático é preciso não esquecer as condições objetivas que determinam o professor que o vai utilizar. Sabe-se que o livro depende do professor, uma vez que não o pode substituir. Por outro lado, sabe-se também que o professor depende do livro, pois este se lhe apresenta como um recurso indispensável. Portanto, a questão toda está em se produzir o livro didático que seja um estímulo constante para a atividade criadora do professor e lhe mantenha vivo o gosto pelo ensino. Tradicionalmente, o livro didático tem sido, frequentemente, um fator de cristalização da rotina. Para se transformar o livro num instrumento de valorização do professorado, essa situação terá de ser alterada. (SAVIANI, 1996, p. 113).

Com tais compreensões e na efervescência da criação de novas cartilhas e alguns jogos pedagógicos "acontece a iniciativa e a concretização, em 2002, do projeto de elaboração de livros 
didáticos contextualizados para o Semiárido, que se tornariam os livros Conhecendo o Semi-Árido1 e $2^{3}$, publicado em 2005" (LINS, 2010, p. 20), pois a preocupação era agora, não somente com as educadoras e educadores, mas também com estudantes e, "reconhecendo o potencial formador que têm os materiais didáticos utilizados nas escolas o IRPAA se lança na experiência de elaboração de livros didáticos contextualizados." (LINS, 2010, p. 20). Posteriormente, ao ocupar espaço nas discussões propostas pela RESAB, os livros didáticos Conhecendo o Semiárido 1 e 2 se inserem no conjunto de mobilizações da Rede e ganham corpo junto às ações da mesma, onde todos os direitos sobre os livros didáticos estariam sob responsabilidade da RESAB.

Ou seja, a produção dos livros didáticos "Conhecendo o Semiárido 1 e 2" não é algo isolado, faz parte de um contexto histórico de lutas e labutas de quem, de fato, acredita na potencialidade da Educação Contextualizada. Nesse entorno, os livros didáticos "Conhecendo o Semiárido 1 e 2" surgem da perspectiva da Educação Contextualizada para a Convivência com o Semiárido em compreender a necessidade que os educandos têm de uma prática dinâmica, crítica e reflexiva, preparando sujeitos mais conscientes e responsáveis na sociedade, objetivando um saber complexo e concreto, fundamentais ao desenvolvimento da vida dos indivíduos em sociedade no Semiárido Brasileiro.

\section{O Livro Didático e suas contribuições para a prática pedagógica}

Apesar de realizarmos uma busca densa sobre a existência de referenciais teóricos consistentes sobre o os principais órgãos de monitoramento do livro didático no Brasil, não foram muitos os trabalhos de base aprofundada encontrados que trazem a discussão sobre a criação do Instituo Nacional do Livro (INL), Comissão Nacional do Livro Didático (COLTED) - inicialmente havia sido denominada: Conselho do Livro Técnico e do Livro Didático (COLTED) que teve como responsabilidade "gerir e aplicar recursos destinados ao financiamento e à realização de programas e projetos de expansão do livro escolar e do livro técnico, em colaboração com a Aliança para o Progresso" (Decreto n 58.653/66). Ainda em 1966 (ano do decreto) o Ministro da Educação promulgou novo Decreto, $\mathrm{n}^{\circ} 59.355 / 66$, que modificou a nomenclatura da COLTED, passando a denominar-se Comissão do Livro Técnico e do Livro Didático, permanecendo com a mesma sigla e o Programa Nacional do Livro Didático (PNLD).

As principais mudanças podem ser destacadas pela criação do Ministério da Educação e Saúde Pública em 1930; a reestruturação do ensino secundário com o decreto n. 19.890 em 1931 e a

\footnotetext{
${ }^{3}$ Segundo Lins (2010) esse título foi democraticamente nomeado em uma das assembleias da RESAB.
} 
constituição promulgada em 1934 que estabeleceu a centralização do ensino pela União, responsável por fixar o plano nacional de educação (BRASIL, 1934). Com o Estado Novo, a partir de 1937, a centralização da educação se intensificou. A criação do INL se dá a partir da transformação do Instituto Cairu em INL, a partir do decreto ${ }^{\circ} 93$ datado de 21 de Dezembro de 1937, assinado por Getúlio Vargas e Gustavo Capanema "a quem o instituto era diretamente subordinado, pela relação institucional com o Ministério da Educação e da Saúde Pública [...]" (GALUCIO, 2009, p. 54) até porque a criação do INL fora uma ação de tal ministério, que estava sob responsabilidade do próprio Capanema, o qual reconhecia o estado como o principal responsável por "proteger o livro, não só promovendo e facilitando a sua produção e divulgação, mas ainda vigilando no sentido de que ele seja, não o instrumento do mal, mas sempre o inspirador dos grandes sentimentos e das nobres causas humanas." (BRASIL. Decreto-Lei n. 93/1937. DOU, 27/12/1937, p. 25586).

A princípio o INL criou três subprogramas o Programa do Livro Didático para o Ensino Fundamental (PLIDEF); o Programa do Livro Didático para o Ensino Médio (PLIDEM) e Programa do Livro Didático para o Ensino Superior (PLIDES). Posteriormente, foram acrescentados o Programa do Livro Didático para o Ensino Supletivo (PLIDESU) e o Programa do Livro Didático para o Ensino de Computação (PLIDECOM). Atualmente o PNLD é compreendido como o maior programa governamental de aquisição e distribuição de livros didáticos do mundo (MANTOVANI, 2009).

Foi por meio do PNLD que o MEC iniciou a distribuição dos livros didáticos em fevereiro de 1986 para alunos de $1^{\circ}$ grau das escolas públicas. Com o fim da ditadura militar instaurou-se no Brasil "uma ordem de redemocratização o que fez com que as políticas educacionais ganhassem um caráter mais social" (FEIJÓ; AMORIM \& RODRIGUES, 2012, p. 73). Sobre tais mudanças, Filgueiras (2011, p. 04) comenta com esse momento de redemocratização do país "o Programa Nacional do Livro Didático objetivava adquirir e distribuir livros didáticos gratuitamente, para os alunos de primeira a oitava séries do ensino fundamental das escolas públicas brasileiras", no entanto em 1992 a proposta de distribuição dos livros até a oitava série foi afetada pelas limitações orçamentárias que ocasionaram um recuo na abrangência da distribuição, restringindo-se o atendimento até a $4^{\mathrm{a}}$ série do ensino fundamental (BRASIL, 2015).

Para atender às novas demandas, o PNLD constituiu dois marcos estruturais. O primeiro foi sua própria instituição e o segundo, já em 1995, durante o governo Fernando Henrique Cardoso 
assegurando recursos para distribuição dos materiais, o que instituiu a consistência do PNLD, Filgueiras (2011).

Como podemos identificar em todo esse percurso, as políticas nacionais de produção, avaliação e distribuição dos livros didáticos foram sofrendo alterações até se chegar ao atual PNLD e às atuais políticas. Desde então as avaliações dos GT's constataram concepções “estratificadas, obsoletas e errôneas" (BRASIL, 1994, p. 103) presentes nos livros didáticos e que por meio destes eram veiculadas em escolas do país.

Devemos considerar, no entanto, que mesmo com as crescentes mudanças que foram ocorrendo, tanto no PNLD quanto na produção dos livros didáticos, que estes ainda não conseguiram alcançar um grau de melhorias significativas na produção e escolha desses livros de modo a promover a potencialização da contextualização no processo de ensino-aprendizagem mesmo porque, devemos questionar se isso de fato tem sido pauta tanto para o MEC quanto para as editoras ${ }^{4}$. Principalmente por ser um material que tem, ao longo do tempo, ocupado lugar central na orientação da estruturação do trabalho pedagógico, pois existem ainda "professores que neles buscam legitimação e apoio para suas aulas [...]" (CORACINI, 2011, p. 11).

É com o olhar sobre o engessamento de conteúdos difundidos via livro didático que se tecem as discussões sobre a colonização deste em seu percurso histórico e seu descolamento das diversidades dos contextos existentes nos processos de ensino e aprendizagem. Reconhecemos que o livro didático, ainda opera como fonte de informação utilizada em sala de aula e orientador dos planejamentos e práticas (CORACINI, 2011), o que reivindicamos é que esses livros precisam ser também e, fundamentalmente, uma das possibilidades de rompimento de uma educação hegemônica que ainda está atrelada a

...resquícios de uma política colonizadora, que, pelos modos de organizar a educação
escolar da América Portuguesa, decretou modelos pedagógicos eurocêntricos,
determinando currículos, utensílios escolares e especialmente livros didáticos a serem
utilizados nos processos de ensino-aprendizagem. Romper com essas narrativas que trazem
a história fora dos sujeitos, as verdades de poucos que não traduzem as pessoas implicadas
na relação pedagógica, é uma possibilidade de contar outra história no cenário educacional,
de dar sentido aos artefatos e processos mobilizados na realização da educação. (PEREIRA,
2012, p. 16).

Ainda discutimos que quando do processo educativo, no ambiente da sala de aula e no caminhar do ensino-aprendizagem, não se permite aos estudantes a possibilidade de mudança de respostas (das que já estão dadas, seja pelos livros/professores/conteúdo) ou outra perspectiva na

\footnotetext{
${ }^{4}$ Um exemplo dessa pouca preocupação é a Base Nacional Curricular Comum (BNCC), a qual destina apenas $40 \%$ de seu espaço para as contextualidades territoriais no ensino.
} 
elaboração de seus textos, redações com uma compreensão de forma crítica, a atividade não passará de cópia, reforçando-se assim, tanto o desmazelo dos livros frente à descontextualização quanto à negligência do professor em face à continuidade da reprodução de meras cópias de uma afirmativa unilateral do que já está dado.

Na verdade, o livro didático, por também fazer parte das políticas de currículo, orienta os processos pedagógicos onde, nesses processos, os estudantes vão produzindo, além da construção do conhecimento, produtos, entre textos, redações, resenhas e, principalmente o discurso e a construção da identidade.

Entendemos que não é possível contemplar os múltiplos contextos e diversidades existentes em dimensões mais aprofundadas nas produções dos livros didáticos, por compreender que, até mesmo dentro dos contextos existem os microcontextos que se desvelam nas vivências dos sujeitos, por isso, defendemos que mesmo com a produção e distribuição de livros didáticos por ventura contextualizados, se os docentes não tiverem garantido um processo de formação continuada/permanente, o que se torna condição sine qua non para a melhoria da sua prática, os conhecimentos presentes poderão ser tratados de maneira mais uma vez universalizantes a partir do local, ou seja, localista e sem problematização, portanto, a crítica será sempre fundamental no processo de contextualização do saber.

Atualmente o livro didático oficial ${ }^{5}$ apresenta-se como um grande aliado do professor à sua prática pedagógica, na verdade o livro didático surge como uma ferramenta essencial de sistematização da informação, pois ele já traz uma carga de conhecimentos e experiências acumuladas ao longo do tempo. Dessa forma, passa a ter como principal função, estruturar o trabalho pedagógico do professor de acordo com as disciplinas e propostas curriculares. O problema, no entanto, surge quando os conteúdos curriculares são apresentados estereotipados e engessados por uma cultura dominante.

O debate em torno da necessidade da elaboração de livros didáticos contextualizados não acontece "da noite para o dia", é um processo que passa pelo crivo das discussões, lutas e embates por uma educação que pensa a potencialidade, na proposição de novos paradigmas para a educação do lugar em que se desenvolve. Entretanto, a criação de um novo paradigma não é suficiente, são necessárias novas subjetividades, pois "não basta criar um novo conhecimento, é preciso que

\footnotetext{
${ }^{5}$ Quando dizemos do livro didático oficial ou livro didático comum, falamos dos livros produzidos pelas grandes editoras e vendidos ao MEC. Estes são postos como oficiais justamente por serem afirmados por um órgão oficial federal. Os livros didáticos "Conhecendo o Semiárido 1 e 2" ainda não são oficiais, mas é fruto de experiências incipientes que pautam a produção de novos materiais e, inclusive o rompimento do cartel das editoras brasileiras.
} 
alguém se reconheça nele" (SANTOS, 1997, p. 287) e para esse reconhecimento dos sujeitos, a proposta de elaboração dos livros didáticos contextualizados surge como uma possibilidade de dar visibilidade às realidades existentes e empoderar os sujeitos tornando-os ativos em seu processo de ensino e aprendizagem.

Desse modo, esse campo de debates que se designa "Educação Contextualizada para Convivência com o Semiárido Brasileiro", surge da necessidade de suscitarmos outras perspectivas sobre o Semiárido Brasileiro, descolonizando a educação para a sua necessária contextualização (MARTINS, 2006), que estejam, inclusive para além das questões geoambientais. Rompendo assim, os estereótipos e estigmas sociais que historicamente se atribuíram às nossas gentes, como falácias que funcionam como sustentáculos de uma lógica de dominação erigida por uma epistemologia que impossibilita o reconhecimento da coexistência de diferentes formas de ser no mundo desvalorizando e distanciando-se das problemáticas antropossociais.

Essa descolonização (como também poderíamos chamar de decolonialidade) vai emergir das próprias transformações sociais na concepção de ciência e também da educação, provenientes de novas dizibilidades que anunciam a importância de uma educação que provoque docentes e discentes a ousarem conhecer o lugar em que vivem, dizibilidades essas exprimem a necessidade de extrair da educação a cultura dominante e a colonialidade historicamente imbricadas em todas as suas formas de saberes (QUIJANO, 2002), (LANDER, 2005), (MARTINS, 2006), e, consequentemente na prática pedagógica e nos materiais didáticos utilizados (FARIA, 1989), (PIMENTEL, 2002), (REIS, 2011), principalmente porque os livros didáticos “costumam ser fontes de visões demasiadamente etnocêntricas" (SACRISTÁN, 1995, p. 89).

Desse modo, o exercício de tecer os processos educativos baseados na contextualização, opera como uma forma necessária de descolonização. Necessária porque busca romper com o modelo dominante de uma educação reificadora, que insere e robustece a perspectiva colonialista, num currículo que reforça:

A história indígena pautada na visão do colonizador, bem assim do negro, via a negação dos valores das suas origens; da mulher, pelo machismo secular; da criança, via o adultocentrismo que permanece nos manuais pedagógicos; do homossexual, pautado numa sociedade sexualmente hipócrita, religiosamente orientada para e pela homofobia. (MACEDO, 2011, p. 22).

Essa ainda é a pauta que reflete as disseminações ideológicas dos nossos currículos, das nossas formações e materiais didático-pedagógicos. Homogeneizadora porque classifica os sujeitos desconsiderando suas diversidades; colonialista porque constitui-se em bases monorreferenciais e 
engranza suas concepções nas minorias em detrimento de outras culturas e distanciando destas a construção da identidade própria nos processos educativos.

[...] a arrasadora presença das culturas que podemos chamar de hegemônicas. As culturas ou vozes dos grupos sociais minoritários e/ou marginalizados que não dispõem de estruturas importantes de poder costumam ser silenciadas, quando não estereotipadas e deformadas, para anular suas possibilidades de reação. (SACRISTÁN, 1995, p. 161).

Referindo-se ao Semiárido Brasileiro sobre o distanciamento do pertencimento na construção da identidade, Lins; Souza \& Pereira (2006, p. 118) argumentam que muitas vezes os sujeitos "não se percebem como parte dessa região, clima ou ecossistema, uma vez que todo o processo histórico-educacional tem tendenciado para isso", nesse caso, o todo que permeia o contexto educacional vai desde o currículo até a merenda escolar que, desconexos dos contextos em que vivem os sujeitos, reforçam o processo de colonialismo dos mesmos, "onde valores, gostos, gestos, linguagens, sentimentos se sobrepõem a outros” (LINS; SOUZA \& PEREIRA, 2006, p. 116).

Esses aspectos que se sobrepõem/impõem nas falas, espaços, discursos reforçam características negativas de determinadas realidades em detrimento de outras, trazendo sempre um discurso de desvalorização do outro e colocando-o como inferior nos patamares sociais, culturais, políticos etc. Nesse sentido, o conjunto de elementos que se reproduzem no âmbito escolar, também conta com o livro didático como aliado na/para a reprodução de estereótipos (SENA, 2012), (CARDOSO, 2009).

É com esse olhar sobre os conteúdos curriculares estereotipados que se tecem as discussões sobre a colonização do livro didático em seu processo histórico e a reprodução de estereótipos como a reprodução da imagem negativa do negro, do nordestino, etc. Pois esses estereótipos são trazidos também através do livro e "é por via do livro didático que muitas vezes ignoramos o nosso pertencimento ao chão Semiárido que habitamos, negamos nossa naturalidade e nos impomos outras formas de colonização”. (PEREIRA, 2012, p.153).

É por essas questões que se faz necessário um diálogo entre a Educação Contextualizada (seja ela para a convivência com o Semiárido, com o Campo, com a Floresta, etc.) e o livro didático; ambos precisam se conhecer no percurso de produção para que cada um possa contribuir para a aprendizagem significativa dos educandos. A Educação Contextualizada na realidade precisa ser uma prática conhecida das pessoas que inventam e reinventam a produção de materiais didáticos para que essas possam dialogar entre si e assim produzir um material que faça sentido na vida prática de educandos e professores. 
$\mathrm{O}$ acesso a livros didáticos adequados às realidades das crianças e adolescentes que vivem no Semiárido ainda é limitado, além disso os materiais são escassos, não abordam de forma positiva aregião onde vivem os sujeitos aprendentes e não favorecem a comunicaçãoentre as áreas do conhecimento. Propondo uma das saídas para sanar esta lacuna, a Rede de Educação do Semiárido Brasileiro (RESAB) reuniu autores,convocou estudiosos, sistematizou experiências municipais de Educação Contextualizada e convidou um grupo de educadoras para elaborar um novo material, focando as especificidades do Semiárido, suas possibilidades e potencialidades.

Por isso, a proposta tecida a partir do paradigma da Convivência com o Semiárido surge de parceria entre a RESAB e o Fundo das Nações Unidas para a Infância (UNICEF) que lançaram o desafio da elaboração de um material didático que pudesse servir como subsídio a professores e educandos. Eram os primeiros livros didáticos no contexto do Semiárido Brasileiro intitulados Conhecendo o Semiárido 1 e 2 onde Lins (2012, p. 65) autentica:

Essa experiência parte da necessidade de criar materiais específicos e contextualizados, e está conectada à provocação de criação de instrumentos estratégicos que sugira a descolonização do currículo a partir da elaboração de novos materiais didáticos que possam construir outras representações do Semiárido, revisando conteúdos, ilustrações e narrativas discursivas.

Os livros "Conhecendo o Semiárido 1 e 2" foram elaborados pelas autoras Claudia Maisa Antunes Lins, Edineusa Ferreira Souza e Vanderléa Andrade Pereira e desde o início da proposta de elaboração de um material contextualizado até receberem o produto do trabalho em mãos, as autoras encararam o desafio de que é possível se produzir um material de qualidade construído a partir da perspectiva da gestão dos múltiplos saberes. Entretanto, também deve-se levar em consideração que o material didático ou paradidático contextualizado não quer criar uma nova colonização. Corrobora Lins (2011, p. 99) quando afirma:

Esses materiais didáticos contextualizados não pretenderam criar uma identidade universal e homogeneizante, mas valorizar os modos de vida e os saberes locais, e nesse sentido as áreas do conhecimento servindo a essa leitura. $\mathrm{O}$ fato é que nós absorvemos como verdades absolutas, produzidas pela ciência, e passamos a resolver (na escola) problemas que só existem nos livros didáticos, e relacionamos muito pouco com o nosso cotidiano, com nossa história, com nossa cultura.

O livro didático, portanto, continua sendo o facilitador do conhecimento, uma grande fonte de informação e, a partir da Educação Contextualizada, apresenta-se como potencializador de uma aprendizagem com sentido e significado na vida dos sujeitos uma das possibilidades de rompimento da Educação colonizadora e hegemônica.

\section{Gêneros textuais e as Novas Linguagens no Livro Didático Contextualizado}


Até o início do século XX os gêneros textuais estavam ligados aos gêneros literários, no entanto hoje em dia a compreensão de gêneros textuais transcende a da literatura. Estes por não serem estanques avançam com o advento das tecnologias (em sua intensidade de uso), o que favorece o surgimento de formas inovadoras dos gêneros textuais a partir de outros gêneros já existentes.

Atualmente a definição de gêneros textuais que respalda nosso trabalho está em compreendê-los como "formas culturais e cognitivas de ação social corporificadas de modo particular na linguagem" (MARCUSCHI, 2011, p. 18). Os compreendemos dessa forma por não os associar a estruturas rígidas ou estanques que em nada dialogam com as formas culturais.

Ao reconhecermos a importância dos gêneros textuais propomo-los como facilitadores de uma aprendizagem dinâmica e contextualizada, corroborando com a recomendação dos Parâmetros Curriculares Nacionais $(\mathrm{PCN})^{6}$, esta sugere que se trabalhe com a maior variedade possível de gêneros textuais, em particular com aqueles a que os educandos se encontram expostos no seu cotidiano e os que necessitam dominar para ampliar sua competência de atuação social, pois "politizar o ato de pesquisar e pensar alternativas para a vida social é parte intrínseca dos novos modos de teorizar e fazer Linguística Aplicada". (MOITA LOPES, 2006, p. 22).

Partindo de tal pressuposto, por considerar que o livro didático contextualizado deve ser utilizado como um facilitador do acesso ao conhecimento sistematizado e de forma contextualizada, as autoras produziram o material com uma diversidade de gêneros textuais significativa, assumindo que os próprios gêneros textuais são elementos de politização e compreensão das realidades sociais e históricas, uma vez que "o texto é uma (re)construção do mundo e não uma simples refração ou reflexo[...]. Ele refrata o mundo na medida em que o reordena e reconstrói”. (MARCUSCHI, 2008, p. 72).

Por isso é condição basilar compreender os gêneros textuais como algo dinâmico e que não são estanques, contribuindo para ordenar e estabilizar as atividades comunicativas do dia a dia ponderando a importância dos gêneros textuais para a formação dos alunos no tocante às suas habilidades comunicativas. Dessa forma, corroboramos com a perspectiva de Marcuschi (2008) de que as manifestações verbais são expressas por meio de textos realizados em algum gênero:

Gênero textual refere os textos materializados em situações comunicativas recorrentes. Os gêneros textuais são os textos que encontramos em nossa vida diária e que apresentam

\footnotetext{
${ }^{6}$ BRASIL, SECRETARIA DO ENSINO FUndAMENTAL. Parâmetros Curriculares de Língua Portuguesa. Brasília: MEC.1998.
} 
padrões sociocomunicativos característicos definidos por composições funcionais, objetivos enunciativos e estilos concretamente realizados na integração de forças históricas, sociais, institucionais e técnicas. (MARCUSCHI, 2008, p. 155).

Ao contrário dos tipos, os gêneros são entes empíricos pois comunicam-se e expressam-se em desígnios diversos, pois a princípio podem constituir listagens abertas como corroboram Gazola, Teixeira \& Hilgemann (2012, p. 68) ao exemplificar com as indicações: "telefonema, carta pessoal, romance, bilhete, aula expositiva, resenha, cardápio de restaurante etc.”.

Numa perspectiva aprofundada, Bakhtin (2003, p. 283) vai afirmar que "se os gêneros do discurso não existissem e nós não os dominássemos [...] a comunicação discursiva seria quase impossível”. É compreendendo tal afirmativa que o trabalho visa analisar os materiais propostos para desvelar a importância da presença dos gêneros textuais no material analisado e suas contribuições para o alcance de uma melhoria na elaboração de materiais didáticos.

\section{Gêneros textuais nos livros didáticos "Conhecendo o Semiárido 1 e 2"}

É essencial compreender que os gêneros textuais operam como geradores de expectativas decompreensão mútua e que estes não são fruto de invenções individuais, mas desenvolvem-se a partir de formas socialmente maturadas em práticas sóciocomunicativas. Em uma tomada histórica dos processos de desenvolvimento e surgimento dessas formas inovadoras dos gêneros textuais Marcuschi (2007, p. 19) explica que a contribuição das culturas de língua exclusivamente oral em relação aos gêneros foi limitada, mas que essa contribuição foi essencial uma vez que:

\footnotetext{
“após a invenção da escrita alfabética por volta do século VII A. C., multiplicam-se os gêneros, surgindo os típicos da escrita. Numa terceira fase, a partir do século $\mathrm{XV}$, os gêneros expandem-se com o florescimento da cultura impressa para, na fase intermediária de industrialização iniciada no século XVIII, dar início a uma grande ampliação.
}

Nesse sentido, o autor afirma que a tecnologia pode proporcionar um surgimento de formas inovadoras dos gêneros textuais, mas não, necessariamente novas, bem como Bakhtin (1997 apud Marcuschi 2007) que já falava em transmutação dos gêneros onde há assimilação de um gênero por outro gerando novos gêneros e enriquecendo, ainda mais a teia dos gêneros textuais.

Por serem "artefatos culturais construídos historicamente pelo ser humano" (MARCUSCHI, 2007, p. 29), o uso de gêneros textuais nos livros didáticos contribui no processo de ensino/aprendizagem de forma significativa, colaborando para o desenvolvimento de competências linguísticas discursivas, bem como para uma consciência crítica em relação aos aspectos contextuais e textuais dos usos da linguagem para os sujeitos desse processo. 
A pesquisa identificou, nos materiais pesquisados, o uso de receitas, verbetes, músicas, poemas, poesias, cantigas, textos didáticos, fragmento de poema, notas informativas. De acordo com Vanderléa Pereira, uma das autoras dos livros Conhecendo o Semiárido 1 e 2 "a música e a poesia surgem como possibilidade de trazer os conteúdos em outras linguagens que estão presentes na vida das pessoas e muitas vezes não nos damos conta de que nos ensinam e muito sobre o meio e suas relações" por isso se percebe que os gêneros textuais utilizados pelas autoras são, geralmente, abordados para introduzir um determinado conteúdo e, para todos os gêneros textuais expostos, há sempre elementos imagéticos que colaboram para uma melhor visualização dos conteúdos apresentados como mapas, fotos, tabelas, etc.

Também foi questionado às autoras sobre a diferença dos gêneros textuais utilizados nos livros didáticos contextualizados em comparação aos livros didáticos comuns/oficiais, onde foi obtida a seguinte resposta:

A principal estratégia foi de comunicar beleza em umapaisagem que sempre foi enfeiada. Se um professor vai trabalhar os gêneros presentes nos livros, para mim isso é secundário e só tem sentido e significado se os conhecimentos que estão ali comunicados sejam compreendidos, se o gênero serviu como comunicador de beleza das coisas daqui, dali e de lá.(PEREIRA, V. - entrevista concedida para este trabalho).

O que aparece como elemento diferenciador num comparativo entre o livro contextualizado e o livro comum/oficial é que, na verdade, os gêneros textuais utilizados no livro didático Conhecendo o Semiárido 1 e 2 trazem sempre elementos da realidade do Semiárido em contraposição aos gêneros de livros comuns que reforçam o estigma do povo do Semiárido reproduzindo os estereótipos historicamente construídos. Promovendo, nesse sentido leituras outras que possam 'dar conta':

[...] das demandas da vida, da cidadania e do trabalho numa sociedade globalizada e de alta circulação de comunicação e informação, sem perda da ética plural e democrática, por meio do fortalecimento das identidades e da tolerância às diferenças. Para tal, são requeridas uma visão situada de língua em uso, linguagem e texto e práticas didáticas plurais e multimodais, que as diferentes teorias de texto e de gêneros favorecem e possibilitam. (ROJO, 2009, p. 90).

Nesse sentido os gêneros textuais utilizados pelas autoras não servem como fim e sim como meio para uma aprendizagem contextualizada com sentido e significado abordando as novas e potenciais linguagens a que o professor e aluno podem apropriar-se para ensinar e aprender, pois auxiliam na desconstrução de estereótipos por tanto tempo reforçados nos livros didáticos comuns/oficiais e proporcionam um novo olhar sobre as identidades.

Segundo a professora Maísa Lins uma das autoras do livro, as temáticas exigiam diferenciadas estratégias para abordar um determinado tema, por exemplo: 
Quando queríamos abordar os produtos e o beneficiamento das frutas nativas do Semiárido, queríamos garantir o sabor naturalmente o mel, as frutas entraram e com eles algumas receitas. Como queríamos trazer o saber popular com relação à utilização de plantas para curar doenças também aí entraram receitas de como preparar os remédios caseiros. Queríamos também abordar as brincadeiras infantis e, naturalmente, as músicas foram contempladas. Poemas e poesias entram com as letras de algumas músicas que cantam o Sertão, ou uma música que fala da água como a música de Guilherme Arantes Terra planeta água. (LINS, M. - entrevista concedida para este trabalho).

O que se pode compreender é que não apenas há variedade de gêneros textuais nos livros didáticos Conhecendo o Semiárido 1 e 2, mas que esses gêneros textuais são um forte subsídio para a educadora ou educador, que vai trabalhar com esse material, possa adentrar as questões linguísticas e, principalmente, discorrer sobre as questões culturais que permeiam o Semiárido e suas relações. Como afirma a autora Vanderléa Pereira:

Um dos primeiros pontos foi a tentativa de transgredir o que estávamos vendo nos livros didáticos que pesquisamos(que eram utilizados pelas primeiros anos do Ensino Fundamental da época) e como os lvros não traziam atividades direcionadas à interpretação das leituras ou perguntas e respostas, os gêneros deveriam dar conta de trazer esclarecimentos sem a necessidade de perguntas e respostas direcionadas. Ao ler a história da formiguinha Zanza, passear pelas descrições ambientais e culturais que apareciam ao longo da história, as crianças poderiam, por elas mesmas, problematizar suas compreensões do conhecimento e,compreender esse conhecimento enquanto localização das pessoas no espaço Semiárido e nos seus espaços interiores enquanto pertencentes a esse lugar. Os gêneros aparecem como moldura, a paisagem mesmo é a beleza da comunicação das temáticas. (PEREIRA, V. - entrevista concedida para este trabalho).

Percebe-se portanto que o foco da produção desse material movimentou-se muito mais nas temáticas e nas narrativas de cunho contextual, cultural, histórico e geográfico do Semiárido do que gêneros textuais não deixando de utilizar os gêneros como um pano de fundo para as tessituras contextualizadas às vivências das e dos estudantes, reafirmando que os gêneros "são correias de transmissão que levam a história da sociedade à história da língua”. (BAKHTIN, 2000, p. 285).

Além disso as situações propostas no livro didático contextualizado"Conhecendo o Semiárido 1 e 2" têm como intenção permitir aos educandos viajar pelas histórias e conteúdos dentro de suas realidades locais, o que difere do livro oficial/comum, uma vez que este busca abanger todos os contextos e, ao mesmo tempo, não contempla as miudezas de cada um.

É, necessariamente, nesse ponto que toca a diferença entre um livro didático comun e um livro didático contextualizado, pois este último permite ao educando ver-se e identificar-se como sujeito atuante de sua aprendizagem, nesse sentido, aEducação Contextualizada elege uma necessária mudança dos materiais adotados oficialmente, para Schistek \& Araújo (2003, p. 56) “não basta adaptar livros didáticos existentes, introduzir cosmeticamente imagens e palavras do Semiárido. É necessário reescrever e repensar todos os livros usados nas escolas com base na realidade do Semiárido", pois um material contextualizado viabiliza o aprendizado eficaz do 
educando e sua formação de maneira que possa proporcionar a emancipação dos sujeitos, o desenvolvimento do pensamento crítico e o conhecimento global a partir dos processos locais.

\section{Considerações finais}

Não se nega aqui que os livros utilizados até hoje e até daqui a outros tantos anos não contribuíram/contribuirão para esse processo tão ímpar que é o processo ensino/aprendizagem, mas o que se destaca é que um livro didático contextualizado pode possibilitara problematização das diversidades presentes nas realidades de seus leitores como também, os próprios livros sejam problematizados por essas realidades em seus aspectos multimodais.

Essa prática proposta pela ECSA não é um conhecimento que se fecha em si, mas que se liberta duma Educação reprodutora do conhecimento superficial. Assim, há uma grande importância da articulação e consolidação das políticas públicas de Educação Contextualizada e, é construindo novos conhecimentos a partir das ciências já existentes, das experiências e das identidades, que se colabora para o desenvolvimento dessas políticas para uma Educação humana, sustentável e no Contexto do Semiárido Brasileiro.

Nestes termos, as iniciativas das militâncias em torno da afirmação da contextualização do currículo escolar são ainda necessárias, por serem proposições alternativas ao sistema que está posto, até que este se construa nas bases das diversidades geoambientais, culturais e sociopolíticas das regiões brasileiras, não desconsiderando o todo, tampouco se reduzindo às partes de forma isolada, uma vez que não podemos sair de um universalismo aprisionador para nos agarrarmos a um localismo reducionista, mas a valorização das diversidades, da descolonização e das contextualidades deve obrigatoriamente concentrar esforços para a compreensão da complexidade das diferentes gentes e suas formas de ser e de existir em seus territórios.

É no sentido de descontruir o formato de educação domesticadora que estamos a favor. Para tanto, os livros didáticos contextualizados tornam-se uma possibilidade de subsidiar essa prática nesse contexto específico de seu território; de igual forma, defendemos que para outros territórios, outros materiais que construam novas dizibilidades e visibilidades sobre as diversidades específicas precisam ser construídos.

\section{Referências}


BAKHTIN, M. Estética da criação verbal. 4. ed. São Paulo: Martins Fontes, 2003.

BRASIL. Constituição da República dos Estados Unidos do Brasil, de 16 de julho de 1934. Diário Oficial da República Federativa do Brasil, Brasília, DF, jul. 1934. Disponível em:http://www.planalto.gov.br/ccivil_03/constituicao/.htm. Acesso em: 21/03/2015.

. Decreto-Lei no 93/1937. Cria o Instituto Nacional do Livro. Diário Oficial da União. 27/12/1937, p. 25586. Disponível em: http://www2.camara.leg.br/legin/fed/declei/19301939/decreto-lei-93-21-dezembro-1937-350842-publicacaooriginal-1-pe.html. Acesso em: 21/03/2015.

BRASIL. Portaria no 2.963 de 29 de Agosto de 2005, Dispõe sobre as normas de conduta para o processo de execução dos Programas do Livro. Publicação no DOU 167, de 30/08/2005.Disponível em: http://www.fnde.gov.br/arquivos. Acesso em: 21/03/2015.

CARDOSO, J. M. O.de C. O ser sertanejo a partir de vários outros olhares: olhos que avistam o sertão dentro da escola. In: Múltiplos espaços para o exercício da contextualização. Selo Editorial RESAB: Juazeiro/BA, 2009.

CARVALHO, Luzineide Dourado e SCHISTEK, Harald. A formação histórico-geográfica do Semiárido Brasileiro. In: Educação e Convivência com o Semiárido: Reflexões por dentro da UNEB. Juazeiro: UNEB/NEPEC-SAB/MCT/CNPQ/INSA/Selo Editorial RESAB, 2011.

CORACINI, M. J. Interpretação, autoria e legitimação do livro didático. São Paulo: Pontes, 2011.

FARIA, A. L. G. de. Ideologia no livro didático. 2. ed. São Paulo: Cortez, 1989.

FEIJÓ, J. A. AMORIM, F. M. RODRIGUES Y. K. S. Políticas públicas de provisão para os Livros Didáticos no Brasil: histórico e estudo de caso. Atos de pesquisa em educação - PPGE/ME FURB. 2012

FILGUEIRAS, J. M. A Educação Moral e Cívica e sua produção didática: 1969-1993. Trabalho de Conclusão de Curso, Dissertação (Mestrado em Educação). Pontifícia Universidade Católica de São Paulo, 2006.

GADOTTI, M. Qualidade na educação: uma nova abordagem. São Paulo: Editora e Livraria Instituto Paulo Freire, 2010.

GALUCIO, A. L. X. Civilização Brasileira e Brasiliense: trajetórias editoriais, empresários e militância política. Trabalho de Conclusão de Curso, Tese (Doutorado em Educação). Universidade Federal Fluminense, 2009.

GAZOLA, D. TEIXEIRA, T. S. HILGEMANN, C. M. A abordagem dos gêneros textuais nos livros didáticos. REVISTA DESTAQUES ACADÊMICOS, VOL. 4, N. 2, 2012 CCHJ/UNIVATES.

LANDNER, E. A colonialidade do saber: eurocentrismo e ciências sociais. Perspectivas latinoamericanas. Ciudad Autônoma de Buenos Aires, Argentina: 2005. 
LINS, C. M. A.; SOUSA, E. F.; \& PEREIRA, V. A. Educação para a convivência com o SemiÁrido: a proposta de elaboração de um livro didático. In: Educação para a convivência com o Semi-Árido: reflexões teórico-práticas. Selo Editorial RESAB: Juazeiro/BA, 2006.

LINS, C. M. A. Conhecendo o Semiárido 1 e 2: Narrativas de uma experiência. Trabalho de Conclusão de Curso, Dissertação (Mestrado em Educação) Universidade Federal da Bahia. Salvador/BA, 2010.

\section{LINS, C. A. Livros didáticos contextualizados conhecendo o Semiárido 1 e 2: aspectos} políticos/pedagógicos no percurso de elaboração. In: Educação e Convivência com o Semiárido: Reflexões por dentro da UNEB. Juazeiro: UNEB/NEPEC-SAB/MCT/CNPQ/INSA/Selo Editorial RESAB, 2011.

\section{Algumas anotações - reflexões sobre a Educação Contextualizada a partir da experiência da feitura dos livros "Conhecendo o Semiárido 1 e 2". In: Educação Contextualizada: fundamentos e práticas. Edmerson dos Santos Reis e Luzineide Dourado Carvalho (Orgs.). Juazeiro/BA. UNEB/NEPEC-SAB/MCT/CNPQ/INSA/Selo Editorial RESAB, 2012.}

LINS, D. Mangue'sschool ou por uma pedagogia rizomática. Campinas: Educação \&. Sociedade, vol. 26, n. 93, p. 1229-1256, set - dez 2005.

MANTOVANI, K. P. O Programa Nacional do Livro Didático: Impactos na qualidade do Ensino Público. Trabalho de Conclusão de Curso, Dissertação (Mestrado em Educação). Universidade de São Paulo. São Paulo: 2009.

MARCUSCHI, L. A. Gêneros textuais: definição e funcionalidade.In: Gêneros textuais e ensino. DIONISIO, Angela Paiva. MACHADO, Anna Rachel e BEZERRA, Maria Auxiliadora. - 5.ed. Rio de Janeiro: Lucerna, 2007.

2008.

. Produção textual, análise de gêneros e compreensão. São Paulo: Parábola Editorial,

. Gêneros textuais: configuração, dinamicidade e circulação. In: KARWOSKI, A. M.; GAYDECZKA, B.; BRITO, K. S. (Orgs.). Gêneros Textuais: reflexões e ensino. 4. ed. São Paulo: Parábola Editorial, 2011.

MARTINS, J. da S. Anotações sobre a interação em rede. In: Educação para a Convivência com o Semiárido: Reflexões teórico-práticas. $2^{\mathrm{a}}$ ed.Juazeiro/BA: Secretaria Executiva da Rede de Educação do Semiárido Brasileiro, Selo Editorial RESAB, 2006.

MACEDO, R. S. Atos de currículo formação em ato?: para compreender, entretecer e problematizar currículo e formação. Ilhéus: Editus, 2011.

MALVEZZI, R. Semi-Árido - uma visão holística. Brasília: CONFEA, 2009.

MENEZES, D. O outro Nordeste: ensaios obre a formação social e política do Nordeste da "Civilização do couro" e suas implicações históricas nos problemas gerais. 2 Ed. Rio de Janeiro: Artenova, 1970.

MOITA LOPES, L. P. Linguística aplicada e vida contemporânea: problematização dos construtos que têm orientado a pesquisa. In: MOITA LOPES, L. P. (Org.). Por uma linguística aplicada indisciplinar. São Paulo: Parábola, 2006. 
PEREIRA, V. A. O livro didático no cotidiano da prática pedagógica de professoras: usos que se revelam no semiárido brasileiro. Teresina: 2012. Dissertação de Mestrado.

PIMENTEL, A. O elogio da convivência e suas pedagogias subterrâneas no Semi-Árido

Brasileiro. Trabalho de Conclusão de Curso, Tese (Doutorado em Educação). Universidade Federal do Rio Grande do Sul, 2002.

QUIJANO, A. Colonialidade, poder, globalização e democracia. In: Revista Novos Rumos 2002.

REIS, E. dos S. Para além de experiências educativas inovadoras...políticas públicas educacionais contextualizadas. In: Tecendo saberes em Educação, cultura e Formação. Selo Editorial RESAB: Juazeiro/BA, 2007.

. Educação para a Convivência com o Semiárido: Desafios e possibilidades. In: Semiárido Piauiense: Educação e Contexto. INSA. Campina Grande: 2010.

Reflexões por dentro da UNEB. Juazeiro: UNEB/NEPEC/Selo Editorial RESAB, 2011.

ROJO, R. Letramentos múltiplos, escola e inclusão social. São Paulo: Parábola Editorial, 2009.

SACRISTÁN, J. G. Currículo e Diversidade Cultural. In: SILVA, T. T. da. \& MOREIRA, A. F. (Org.). Territórios contestados - o currículo e os novos mapas políticos e culturais. $3^{\mathrm{a}} \mathrm{Ed}$.

Petrópolis/RJ: Vozes, 1995.

SANTOS, B. de S. Pela mão de Alice: o social e o político na pós-modernidade. $3^{\text {a }}$.ed. São Paulo: Cortez, 1997.

SANTOS, J. M. dos. Tecnologias para o Semiárido. In: Semiárido Piauiense: Educação e Contexto. INSA. Campina Grande: 2010.

SAVIANI, D. Educação: do senso comum à consciência filosófica. São Paulo: Editora Autores Associados, 1996.

REIS, E. dos S. Educação para a Convivência com o Semiárido: Desafios e possibilidades. In: Semiárido Piauiense: Educação e Contexto. INSA. Campina Grande: 2010.

SCHISTEK, H. \& ARAÚJO, L. M. A convivência com o Semiárido. Juazeiro/BA: Selo Editorial RESAB, 2007.

SENA, R. R. O. O Semiárido na pauta do livro didático: antigas abordagens e novas perspectivas. Trabalho de conclusão de curso, especialização (Pós Graduação em ECSAB). Universidade do estado da Bahia. Juazeiro/BA: 2012.

SILVA, R. M. da. Entre o Combate à seca e a convivência com o Semiárido: transições paradigmáticas e sustentabilidade do desenvolvimento. Brasília, 2008. Trabalho de Conclusão de Curso, Tese (Doutorado em Desenvolvimento Sustentável) Universidade de Brasília, 2006.

. Concepções de desenvolvimento: convivência e sustentabilidade no Semiárido brasileiro. In: Semiárido Piauiense: Educação e Contexto. INSA. Campina Grande: 2010.

Recebido em: 01.06.2016 Aceito em: 09.02.2017 